\title{
Prevalence of pain 6 months after surgery: a prospective observational study
}

\author{
Rita Laufenberg-Feldmann ${ }^{1 *}$, Bernd Kappis ${ }^{1}$, Susanne Mauff ${ }^{1}$, Irene Schmidtmann² and Marion Ferner ${ }^{1}$
}

\begin{abstract}
Background: Pain after surgery is a major issue for patient discomfort and often associated with delayed recovery. The aim of the present study was to evaluate the prevalence of pain and requirement for analgesics up to 6 months after elective surgery, independent if new pain symptoms occurred after surgery or if preoperative pain persisted in the postoperative period.

Methods: A prospective observational single center cohort study was conducted between January 2012 and August 2013. Eligible patients were scheduled to undergo elective surgical interventions including joint (hip, knee arthroplasty), back (nucleotomy, spondylodesis), or urological surgery (cystectomy, prostatectomy, nephrectomy). Pain was assessed on an 11-point numerical rating scale (NRS) before, on postoperative day 2 and 6 months after surgery. Clinical information was collected with structured questionnaires and by telephone interview.

Results: Six hundred and forty-four patients gave informed consent, including $54.4 \%$ men (mean age 62.2, SD 14.3). Higher preoperative pain scores were found in patients undergoing joint (mean 7.6; $95 \%$ confidence interval [Cl]: 7.2-8.0) and back surgery (mean 7.1, Cl: 6.8-7.5) than in patients prior to urological surgery (mean 2.3; Cl: 1.8-2.8). After 6 months, about $50 \%$ of patients after joint or back surgery indicated pain levels $\geq 3 / 10$, compared to 15 . $9 \%$ of patients after urological surgery $(p<.001) .35 .3 \%$ of the patients after joint surgery and $41.3 \%$ after back surgery still use pain medication 6 months postoperatively, in contrast to $7.3 \%$ of patients after urological surgery. $13.6 \%$ of patients who underwent back surgery indicated the regular intake of opioids.
\end{abstract}

Conclusions: Our results reveal that a significant percentage of patients undergoing procedures in joint or back surgery still need pain medication up to 6 months postoperatively due to ongoing pain symptoms. Improved monitoring of pain management is warranted, especially after discharge from hospital, to improve long-term results.

Trial registration: Clinicaltrials.gov (Identifier: NCT01488617); date of registration December 6th 2011.

Keywords: Postoperative pain, Analgesics, Chronic pain, Outcome

\section{Background}

Postsurgical pain is a major issue for patient discomfort associated with delayed recovery and prolonged hospital stay $[1,2]$ and represents a major, largely unrecognized clinical problem [3]. The intensity of acute postoperative pain increases the risk of developing persistent pain [3] and contributes to postoperative morbidity and mortality [4]. Nerve spare surgical techniques are intended to reduce the risk for neuropathic pain which has been identified as an important cause of long-term postsurgical

\footnotetext{
* Correspondence: rita.laufenberg@unimedizin-mainz.de

${ }^{1}$ Department of Anaesthesiology, University Medical Center of the Johannes Gutenberg University Mainz, Langenbeckstrasse 1, D-55131 Mainz, Germany Full list of author information is available at the end of the article
}

pain, as well as effective early treatment of postoperative pain. In the last two decades guidelines on the management of postoperative pain [5], acute pain services, minimal-invasive surgery and differentiated analgesic therapies have been implemented and evaluated in a national survey in Germany [6]. Multimodal techniques with systemic analgesics should be applied considering the risks and benefits for the individual patient according to Practice Guidelines for Acute Pain Management in the Perioperative Setting [7].

However, the persistence of pain after surgery may lead to functional impairment with consecutive disability and immobility and affect the patients' quality of life. 
Adequate pain management helps to prevent or to diminish postoperative complications, such as respiratory or cardiovascular problems, or postoperative delirium [8-10]. Prevalence and predictors of acute postoperative pain have already been examined [11-16]. There is still a paucity of data to determine the influence of surgical procedure and postoperative pain treatment on longterm pain-related outcome, particularly in patients with preoperative chronic pain.

The aim of this prospective study was to explore the prevalence of pain and requirement for analgesics up to 6 months after elective surgery considering different procedures in joint, back and urological surgery.

\section{Methods}

This single center clinical study was conducted at the Department of Anaesthesiology at the University Medical Center of the Johannes Gutenberg University Mainz, Germany. Data presented here are a subset of a larger data set evaluating outcome variables after major surgery (MOPS-study, Mainz Outcome Predictor Study). Ethical approval for this study [Ethical Committee $\mathrm{N}^{\circ}$ 837.519.11 (8061)] was provided on 3rd January 2012 by the Regional Ethics Committee of RhinelandPalatinate, Mainz, Germany. The study was registered in clinicaltrials.gov (Identifier: NCT01488617). Written informed consent was obtained from all patients. From January 2012 to August 2013 a total of 821 patients undergoing elective surgery were eligible, from whom 644 (78.4 \%) agreed to participate (dropout reasons see Fig. 1, CONSORT-diagram). Surgical interventions included joint surgery (total knee or hip replacement), back surgery (spinal cord decompression with discectomy or hemilaminectomy), and urological surgery (cystectomy, nephrectomy, radical prostatectomy). Urological surgery was predominantly due to cancer.

Eligible patients were aged $\geq 18$ years, were able to read, understand German language and were capable to complete questionnaires.

During preoperative consultation prior to surgery, patients completed a set of questionnaires including socio-demographic and pain variables. Pain intensity was assessed on a numerical rating scale (NRS 0-10 with $0=$ no pain and $10=$ worst possible pain) before surgery, on the second postoperative day, and 6 months after surgery. Pain duration like chronic preoperative pain was defined as pain $\geq 3 / 10$ NRS for at least 6 months. Pain at 6 months after surgery was defined as at least $3 / 10$ on a NRS, corresponding to moderate pain with a potential impact on physical or emotional functioning [17]. Clinical information was collected from medical records and obtained with structured

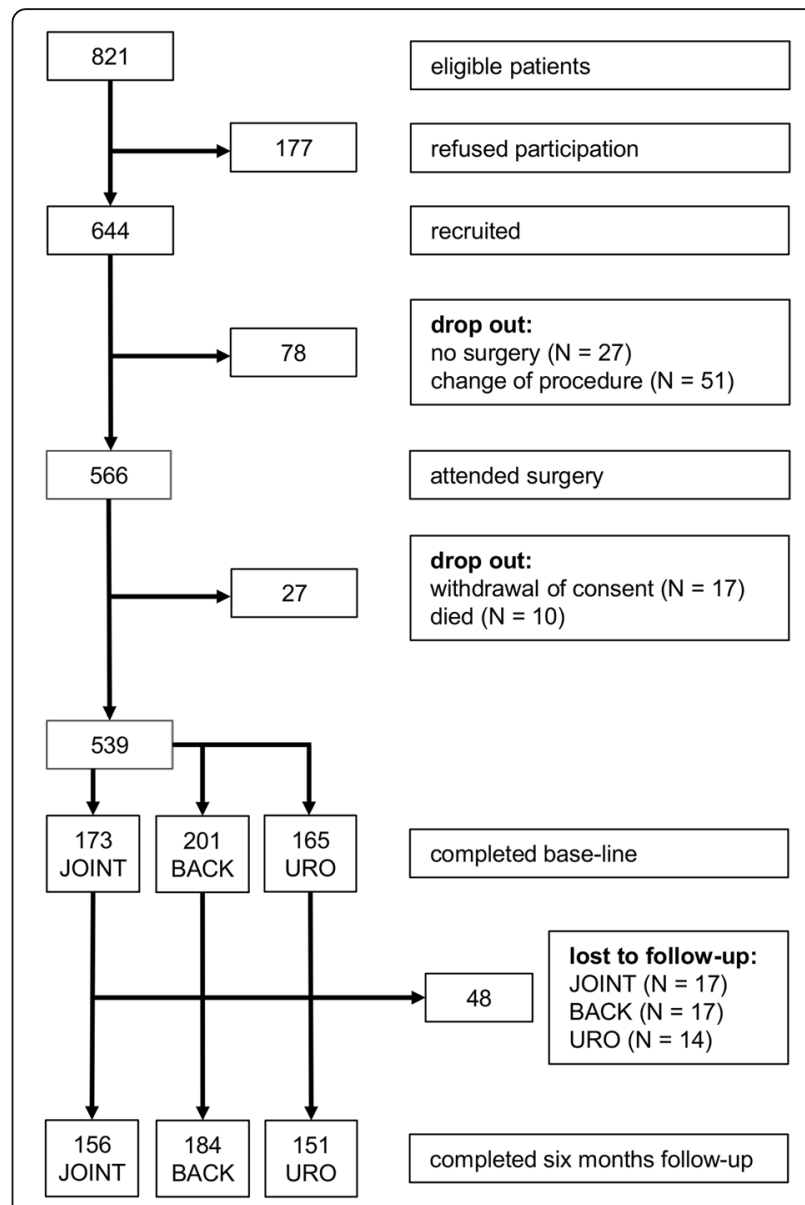

Fig. 1 CONSORT-diagram

questionnaires and by telephone interviews in the follow-up period at 6 months after surgery.

Intraoperative analgesia was obtained with a combination of general anaesthesia and if indicated epidural anaesthesia by a continuous epidural infusion of bupivacaine $0.125 \%$ with fentanyl $2 \mu \mathrm{g} / \mathrm{ml}$ and postoperative supplemented with patient controlled epidural analgesia (PCEA).

Standard postoperative pain treatment in the post anaesthesia care unit (PACU) for patients without epidural catheter consisted of patient controlled intravenous analgesia (PCIA) with piritramide (bolus doses of $1.5 \mathrm{mg}$, lockout time $10 \mathrm{~min}$ ). In addition, patients with PCIA received non-opioids (e.g. intermittent paracetamol IV every $6 \mathrm{~h}$, metamizole IV $5 \mathrm{~g} / 24 \mathrm{~h}$ continuous or NSAIDs). Patients undergoing back surgery received a standard analgesic regimen with non-opioids, supplemented with opioids (15 mg piritramide subcutaneously), if indicated.

On the normal ward, pain treatment is provided and customized twice daily by an acute pain unit, consisting of anaesthesiologists and nursing staff. 


\section{Statistical analysis}

As in this study descriptive data, i.e. prevalences, were analyzed, a formal power calculation was not required. Assuming a prevalence of $40 \%$ for pain 6 months after surgery, recruitment of $N=145$ participants in each surgery group to obtain $95 \%$ confidence intervals of $+/-$ $8 \%$ was required. Descriptive statistics are expressed as absolute and relative frequencies (\%) or mean (SD). Differences between groups were examined using parametric Student's $t$-test or appropriate nonparametric tests (e.g. Kruskal-Wallis Test). Spearman rank correlation ( $r$ ) was used to examine the association between metric variables. Patients with (NRS $\geq 3$ ) and without clinically relevant pain at 6 months were compared using cross tabulation and chi-square-tests.

All analyses were performed using IBM SPSS Statistics for Windows, Version 22 (Released 2013. IBM SPSS Statistics for Windows, Armonk, NY: IBM Corp.). P-value <.05 was considered statistically significant. No adjustment for multiple testing was performed, therefore only the local significance level $\alpha=0.05$ is kept.

\section{Results}

\section{Patients}

From January 2012 to August 2013644 patients agreed to participate, from which 105 patients had to be withdrawn during the further course of the study for different reasons (Fig. 1, CONSORT diagram). Data of 539 patients were entered in the per-protocol analysis, thereof 173 patients underwent joint surgery, 201 underwent back surgery, and 165 patients underwent urological surgery. Mean follow-up time was 25.8 weeks ( $\mathrm{SD}=0.8$ weeks).

\section{Demographic and clinical data}

Demographic and clinical data are shown in Table 1 for each surgery group.

\section{Surgical interventions}

Patients underwent different interventions in orthopedic, neurosurgical and urological surgery. Joint surgery $(N=173)$ included predominantly hip prosthesis $(49.7 \%)$, knee prosthesis $(48.6 \%)$, shoulder prosthesis $(1.7 \%)$. Back surgery $(N=201)$ included discectomy or hemilaminectomy $(77.6 \%)$, spondylodesis (20.9\%), and others (1.5\%). Urological surgery comprised $(N=165)$, patients with cystectomy $(31.5 \%$, with continent or incontinent urinary diversion), nephrectomy (27.3\%), radical prostatectomy (38.2\%), and others (3\%).

Urological surgery was mainly due to cancer (86\%), compared to $1.7 \%$ in joint and $2.5 \%$ in back surgery.
Table 1 Demographic and clinical data

\begin{tabular}{|c|c|c|c|c|}
\hline & Joint & Back & Uro & $p$ \\
\hline N & 173 & 201 & 165 & \\
\hline Age (mean, SD) & $65.8(12.9)$ & $59.0(16.1)$ & $62.4(12.2)$ & $<.001$ \\
\hline Age range & $18.0-85.7$ & $18.4-86.9$ & $18.7-82.1$ & \\
\hline Female (N, \%) & $102(59.0)$ & $103(51.2)$ & $41(24.8)$ & $<.001$ \\
\hline Without partnership (N, \%) & $68(39.3)$ & $57(28.4)$ & $34(20.6)$ & \\
\hline Educational level & & & & .002 \\
\hline Low (\%) & 67.1 & 48.9 & 47.8 & \\
\hline Medium (\%) & 22.0 & 30.0 & 22.6 & \\
\hline High (\%) & 11.0 & 21.1 & 29.6 & \\
\hline BMI (mean, SD) & $30.4(6.5)$ & $28.0(4.9)$ & $27.1(4.6)$ & $<.001$ \\
\hline ASA & & & & .001 \\
\hline ASA $1(\%)$ & 1.7 & 6.5 & 3.0 & \\
\hline ASA 2 (\%) & 45.1 & 50.7 & 65.2 & \\
\hline ASA $3(\%)$ & 51.4 & 41.3 & 30.5 & \\
\hline ASA 4 (\%) & 1.7 & 1.5 & 1.2 & \\
\hline Type of Anaesthesia & & & & $<.001$ \\
\hline General anaesthesia (\%) & 48.0 & 100 & 38.8 & \\
\hline Regional anaesthesia (\%) & 39.9 & - & - & \\
\hline $\begin{array}{l}\text { Combined general + } \\
\text { regional anaesthesia (\%) }\end{array}$ & 12.1 & - & 61.2 & \\
\hline $\begin{array}{l}\text { Duration of surgery [Min.] } \\
\text { (mean, SD) }\end{array}$ & $123(53)$ & $152(85)$ & $273(145)$ & $<.001$ \\
\hline Range & $41-438$ & $26-480$ & $59-652$ & \\
\hline
\end{tabular}

ASA American Society of Anesthesiologists physical status classification system, $B M I$ Body mass index

\section{Pain and pain medication}

Pain data are presented in Table 2 and in Fig. 2. Patients undergoing joint and back surgery had significantly higher preoperative pain scores than patients prior to urological surgery (Fig. 2a, b, and c). Pain ratings did not differ significantly between the groups in the early postoperative period (Fig. 2d, e, and f). After 6 months significant differences between the three surgery groups became apparent (Fig. 2g, h, and i). Patients after back

Table 2 Pain ratings and use of analgesics

\begin{tabular}{lllll}
\hline & Joint & Back & Uro & $p^{*}$ \\
\hline Chronic preoperative pain $^{\mathrm{a}}[\%]$ & 79.2 & 43.8 & 18.8 & $<.001$ \\
Preoperative (mean, SD) $^{\mathrm{b}}$ & $7.2(2.3)$ & $6.8(2.6)$ & $1.6(2.6)$ & $<.001$ \\
2 days postoperative (mean, SD) $^{\mathrm{b}}$ & $4.8(2.7)$ & $4.5(2.9)$ & $4.2(2.7)$ & .136 \\
6 months postoperative (mean, SD) $^{\mathrm{b}}$ & $2.9(2.6)$ & $3.6(2.9)$ & $1.1(1.9)$ & $<.001$ \\
Analgesics at endpoint (\%) $^{c}$ & 35.3 & 41.3 & 7.3 & $<.001$ \\
Non-Opioids at endpoint (\%) $^{c}$ & 31.3 & 34.4 & 6.0 & $<.001$ \\
Opioids at endpoint (\%) $^{c}$ & 8.7 & 13.6 & 2.0 & .001 \\
\hline
\end{tabular}

*Kruskal-Wallis Test, Chi-Square Test, resp

${ }^{a}$ NRS $\geq 3$ and duration at least six months prior to surgery

bPain ratings during movement on a Numeric Rating Scale (NRS) 0-10

${ }^{c}$ Regular intake of analgesics 6 months after surgery 


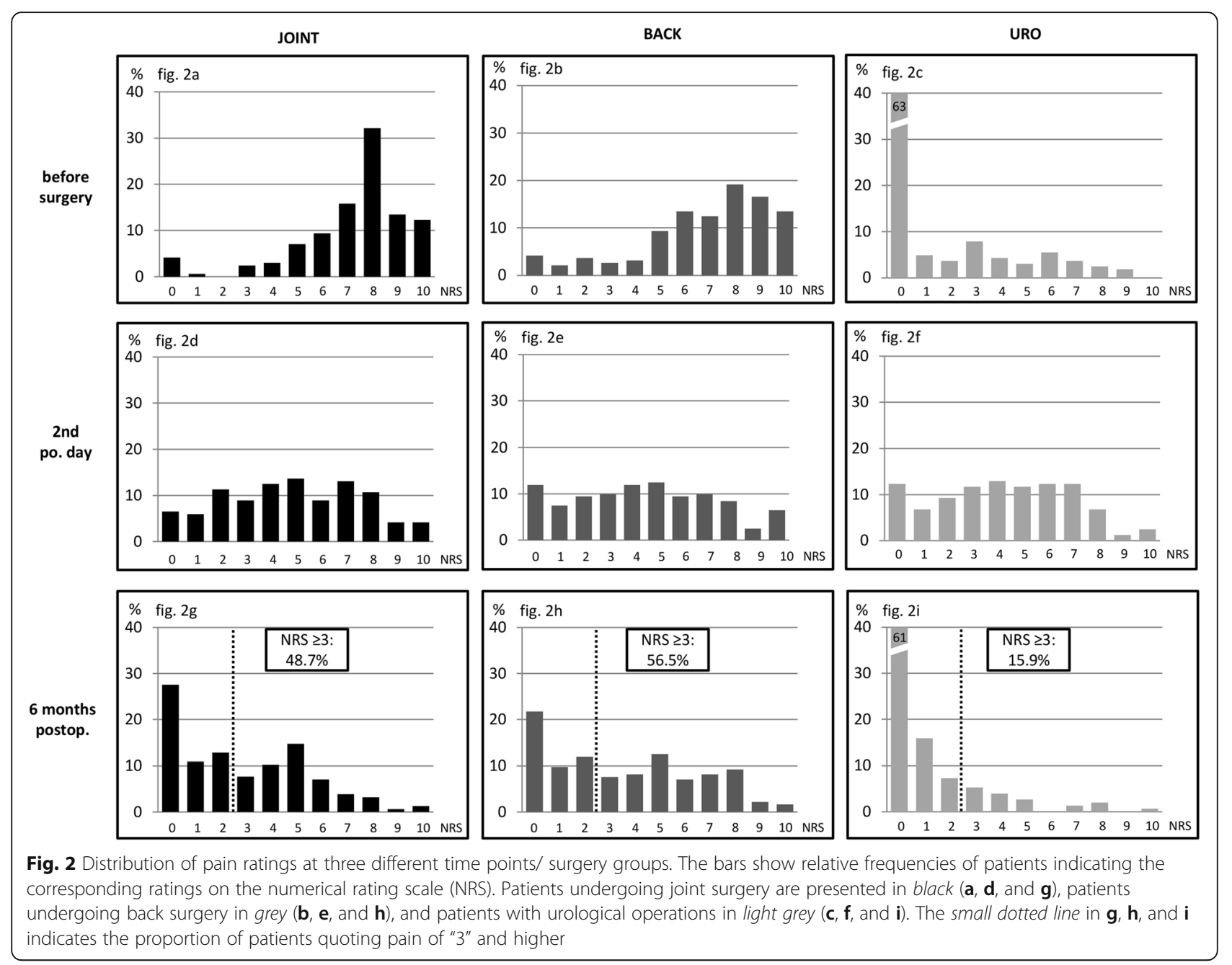

surgery indicated the highest pain scores, followed by joint surgery. After urological surgery patients reported the lowest pain levels at that time.

\section{Sex differences}

Considering the entire sample, women indicated higher mean pain scores than men both preoperatively (6.5 vs. $4.3, p<.001)$ and 6 months after surgery (3.0 vs. 2.3, $p=.005)$, while there were no differences on the second postoperative day. Subdivided into surgery groups, the preoperative gender-specific differences were not confirmed in the joint surgery group $(p=.345)$. Also in the catamnesis, no gender-specific differences were observed in patients undergoing joint $(p=.987)$ and back surgery $(p=.629)$ indicating similar pain levels in men and women in these subsamples, respectively.

With regard to preoperative pain status, there were differences between all groups. Almost $80 \%$ of the patients undergoing joint and $44 \%$ of the patients undergoing back surgery suffered from chronic preoperative pain, while this applied only to a quarter of the patients prior to urological surgery.

Six months after surgery, $35.3 \%$ of the patients after joint surgery and $41.3 \%$ after back surgery still used analgesics (Table 2), in contrast to $7.3 \%$ of patients after urological surgery. $13.6 \%$ of patients who underwent back surgery indicated the regular intake of opioids.

$41.5 \%$ of the patients in our sample experienced clinically relevant pain 6 months after surgery, with different rates in each surgery group (Fig. $2 \mathrm{~g}$, h, and i). After joint and back surgery about every second patient indicated pain levels $\geq 3 / 10$ at that time. However, only $15.9 \%$ of patients after urological surgery reported similar pain levels $(p<.001)$.

Table 3 shows comparisons of different clinical variables between patients with and without clinically relevant pain in each surgery group 6 months postoperatively.

Significant differences between men and women were observed in patients undergoing urological surgery. First, there were only 40 women $(26.5 \%)$ in this group of 151 patients. Furthermore, 63 male patients underwent radical 
Table 3 Comparison of clinical variables between patients with and without pain 6 months after surgery

\begin{tabular}{|c|c|c|c|c|c|c|c|c|c|}
\hline & Joint pain & Joint no pain & $p^{*}$ & Back pain & Back no pain & $p^{*}$ & Uro pain & Uro no pain & $p^{*}$ \\
\hline N (\%) & $76(48.7 \%)$ & $80(51.3 \%)$ & & $104(56.5 \%)$ & $80(43.5 \%)$ & & $24(15.9 \%)$ & $127(84.1 \%)$ & \\
\hline Female (\%) & 56.6 & 60.0 & .39 & 51.9 & 51.3 & .52 & 50 & 22 & .006 \\
\hline Age (mean, SD) & $65.3(12.4)$ & $66.6(13.3)$ & .40 & $61.8(14.9)$ & $60.0(16.6)$ & .062 & $60.5(11.5)$ & $62.8(11.7)$ & .30 \\
\hline BMI (mean, SD) & $30.9(5.5)$ & $30.0(7.3)$ & .053 & $28.9(4.7)$ & $27.1(5.1)$ & .004 & $26.5(4.6)$ & $27.4(4.5)$ & .34 \\
\hline Preoperative Pain Intensity NRS $\geq 3$ (\%) & 94.7 & 92.5 & .41 & 92.3 & 73.8 & .001 & 54.2 & 22.8 & .003 \\
\hline Chronic Preoperative Pain (\%) ${ }^{a}$ & 85.5 & 75.0 & .074 & 54.8 & 30.0 & .001 & 33.3 & 15.7 & .046 \\
\hline Duration of Surgery [minutes] (mean, SD) & $124(56)$ & $123(53)$ & .74 & $154(86)$ & $147(79)$ & .64 & $275(136)$ & $268(147)$ & .62 \\
\hline
\end{tabular}

NRS Numeric Rating Scale

*Kruskal-Wallis Test, Chi-Square Test, resp

${ }^{a} \mathrm{NRS} \geq 3$ and duration at least six months prior to surgery

prostatectomy (RPX), being associated with low postoperative pain scores $(N=63$, mean $=0.6, \mathrm{SD}=0.2)$. Considering surgical interventions that were performed in both men and women (nephrectomies and cystectomies), the comparison of pain scores at 6 months revealed no significant differences (men: $N=52$, mean $=1.1, \mathrm{SD}=2.0$; women: $N=40$, mean $=1.7, \mathrm{SD}=2.4, p=.20$ ). This also applies for the percentage of clinically relevant pain 6 months after surgery $(17.3 \%$ in men vs. $30.0 \%$ in women, $p=.21$ ).

BMI levels were slightly higher in patients who indicated pain compared to patients without pain, however, differences in BMI levels did not reach statistical significance (joint surgery: mean 30.9 vs $30.0, p=0.053$; back surgery: mean 28.9 vs $27.1, p=0.004$ ).

Preoperative pain variables (i.e. pain intensity and duration) differed significantly between patients 6 month after surgery. Patients who suffered from pain at 6 months were more likely to have reported preoperative pain intensity of $\geq 3 / 10$ NRS or to suffer from preoperative pain for more than 6 months prior to surgery.

Considering the duration of surgery, no significant differences between patients with or without pain were noticed between any of the surgery groups (Table 3 ).

\section{Discussion}

The results of the present study demonstrate that a significant number of patients report persistent pain and intake of analgesic medication, even opioids, up to 6 months after surgery.

Considering the different surgery groups, more than $50 \%$ of patients after back and joint surgery indicated clinically relevant pain 6 months after surgery. Patients undergoing joint or lumbar spine surgery for degenerative conditions often have poor outcomes following the surgical intervention, with up to $40 \%$ reporting residual chronic pain $[1,18]$. Many studies on treatment outcome focus on pain ratings in the acute postoperative phase after different surgery $[12,19,20]$, or have investigated prevalence and etiology of persistent postsurgical pain (PPSP) [3, 21-23]. According to the definition by Macrae [24] for persistent postsurgical pain the following criteria should be fulfilled: pain after surgical procedure, pain duration from at least 2 months, excluding other conditions and exclusion from a preexisting problem. Particularly conditions in which surgery escalates pre-existing pain symptoms have to be explored carefully.

Especially in patients with degenerative diseases of joint or vertebral column, the patients' burden of pain often triggers the indication for surgery. Therefore, these patients do not meet the above-mentioned criteria for persistent post-surgical pain. In contrast, in patients undergoing major surgery due to urological tumors, preoperative pain is not a leading symptom.

We decided to follow-up patients up to 6 months after surgery assuming that postoperative rehabilitation programs were completed at that time and prolonged inflammatory processes would have been subsided [24]. Patients in our study who underwent back (or joint) surgery, experienced higher preoperative and postoperative pain levels compared to patients in other studies undergoing surgery of the vertebral column or knee replacement surgery $[18,25]$.

With regard to postoperative pain, patients with renal cancer [21] or with prostate cancer [26-28] indicate low postoperative pain in the catamnesis, which is in agreement with our data. However, self-reported pain levels after urological surgery were lower than in a study evaluating pain in patients after radical prostatectomy, with a significant proportion of patients complaining about pain 3 and 6 months after surgery [26].

In contrast to other studies, we evaluated prevalence and intensity of pain 6 months after surgery in combination with the need for pain medication. We assumed that after joint and back surgery, pain symptoms would improve continuously so that a regular intake of analgesics could be avoided. However pain intensity and pain duration differed between surgical procedures in our study. Especially patients undergoing back or joint surgery appeared to be impaired due to pain up to 6 months 
postoperatively. Consequently, in our sample, about $40 \%$ of the patients after back surgery reported the intake of analgesics 6 months post-surgery, and $13.6 \%$ of these patients even indicated the intake of opioids on a regular basis.

These results are unexpected and show an unsatisfying result of the surgical intervention in terms of pain reduction. Moreover, the long-term intake of opioids in non-cancer pain is not supported by recent clinical practice guidelines [29], since opioids have significant side effects and their analgesic effect is not superior to non-opioids.

Possible explanations for the prolonged intake of analgesics after surgery may be an uncritical prescription of opioids or uncontrolled self-medication with analgesics. In patients undergoing spine surgery, psychiatric co-morbidity may be a risk factor for continued postoperative opioid intake, especially if opioids were already used prior to surgery [30]. Also in patients with total knee replacement the preoperative use of opioids may increase the risk for post-operative pain during the first post-operative week with consecutive higher opioid consumption [31].

More effective pain management strategies already before and after surgery may provide improved surgical outcomes. This may contribute to a better quality of life [32] and may help to prevent persistent pain, whereas insufficient pain management is associated with poorer recovery, and worse quality of life, also on long-term follow-up [16].

Cognitive and behavioral strategies in combination with individualized postoperative rehabilitation programs may also contribute to reduce the patients' burden of pain and provide better surgical long-term results. Avoiding fear of movement and decreased physical function has already shown to be an important aspect e.g. in patients following lumbar spine surgery for degenerative conditions [18].

Some limitations of the study should be considered. For the follow-up period, a longer observational time (e.g. up to 1 year) may have been reasonable in order to evaluate patients with a late improvement of pain symptoms. In addition, during the follow-up period no physical examination was performed in order to evaluate the functional improvement after surgery. Therefore, we could not state on functional success of surgery after physical therapy and rehabilitation programs. Furthermore, we did not discriminate whether the patients with urological surgery received a curative or a palliative intervention. However, since these patients reported the lowest pain levels in comparison to the other groups, before and after surgery, this aspect was not further investigated.

\section{Conclusions}

In conclusion, these data reveal that a significant number of patients suffers from pain and need analgesic medication, even opioids, up to 6 months after surgery. The treatment of ongoing pain after surgery is still an important challenge. The need of preventive therapies should be considered for example in patients with neuropathic pain or patients with chronic opioid use. Besides the evaluation of predictive factors for ongoing postoperative pain and the identification of patients at risk, the improvement of postoperative pain management strategies after discharge should be subject of further research.

\section{Additional file}

Additional file 1: Description of variables. Data set includes sociodemographic pain related, anesthesia-related data as well as data on pain medication. (XLSX $85 \mathrm{~kb}$ )

\section{Abbreviations}

BMI: Body mass index; IV.: Intravenous; NRS: Numerical rating scale; NSAID: Nonsteroidal anti-inflammatory drugs; PACU: Postanaesthesia care unit; PCEA: Patient controlled epidural analgesia; PCIA: Patient controlled intravenous analgesia; PPSP: Persistent postsurgical pain; RPX: Radical prostatectomy; SD: Standard deviation

\section{Acknowledgements}

We would like to thank all patients who participated in the MOPS-study (Mainz Outcome Predictor Study). Special thanks go to Peter Straub for his affectionate patient care and diligent study assistance, and Hans-Jürgen Baldering for his patience and efforts to resolve all software problems. Without their commitment, the study would never have been completed. The study was funded by resources of the submitting authors department only.

\section{Funding}

The study was funded by resources of the submitting authors department only.

\section{Availability of data and materials}

The dataset supporting the conclusions of this article is included within the article (and its Additional file 1).

\section{Authors' contributions}

RLF, BK and MF were responsible for conception and design, initiated data acquisition and drafted the manuscript. SM collected data and was responsible for data management. BK did the statistical analysis and helped drafting the manuscript. IS critically revised the statistical part of the manuscript and made substantial contributions to evaluate the data. All authors read and approved the final manuscript.

\section{Competing interests}

The authors declare that they have no competing interests.

\section{Consent for publication}

All authors gave consent for publication of the manuscript.

Ethics approval and consent to participate

Ethical approval for this study [Ethical Committee N 837.519 .11 (8061)] was provided on 3rd January 2012 by the Regional Ethics Committee of Rhineland-Palatinate, Mainz, Germany.

\section{Author details}

${ }^{1}$ Department of Anaesthesiology, University Medical Center of the Johannes Gutenberg University Mainz, Langenbeckstrasse 1, D-55131 Mainz, Germany. ${ }^{2}$ Institute for Medical Biostatistics, Epidemiology and Informatics (IMBEI), University Medical Center of the Johannes Gutenberg University Mainz, Langenbeckstrasse 1, D-55131 Mainz, Germany.

Received: 21 May 2016 Accepted: 4 October 2016

Published online: 10 October 2016 


\section{References}

1. Apfelbaum JL, Chen C, Mehta SS, Gan TJ. Postoperative pain experience: results from a national survey suggest postoperative pain continues to be undermanaged. Anesth Analg. 2003;97(2):534-40.

2. Gan TJ, Habib AS, Miller TE, White W, Apfelbaum JL. Incidence, patient satisfaction, and perceptions of post-surgical pain: results from a US national survey. Curr Med Res Opin. 2014;30(1):149-60.

3. Kehlet $\mathrm{H}$, Jensen TS, Woolf CJ. Persistent postsurgical pain: risk factors and prevention. Lancet. 2006;367(9522):1618-25.

4. Kehlet $\mathrm{H}$, Wilmore DW. Multimodal strategies to improve surgical outcome. Am J Surg. 2002;183(6):630-41.

5. S3-Leitlinie Behandlung akuter perioperativer und posttraumatischer Schmerzen. Deutsche Interdisziplinäre Vereinigung für Schmerztherapie (DIVS). Deutscher Ärzte-Verlag, Köln. AWMF-Register Nr. 041/001; 2007/05/21 [cited 2016/02/21]; Available from: http://www.awmf.org/.

6. Erlenwein J, Stamer U, Koschwitz R, Koppert W, Quintel M, Meissner W, et al Inpatient acute pain management in German hospitals: results from the national survey "Akutschmerzzensus 2012". Schmerz. 2014;28(2):147-56. Akutschmerztherapie in der stationaren Versorgung an deutschen Krankenhausern : Ergebnisse des Akutschmerzzensus 2012.

7. American Society of Anesthesiologists Task Force on Acute Pain M. Practice guidelines for acute pain management in the perioperative setting: an updated report by the American Society of Anesthesiologists Task Force on Acute Pain Management. Anesthesiology. 2012;116(2):248-73.

8. Kehlet $\mathrm{H}$, Holte $\mathrm{K}$. Effect of postoperative analgesia on surgical outcome. Br J Anaesth. 2001;87(1):62-72.

9. Carney RM, Freedland KE, Miller GE, Jaffe AS. Depression as a risk factor for cardiac mortality and morbidity: a review of potential mechanisms. J Psychosom Res. 2002;53(4):897-902.

10. Hall GM, Salmon P. Physiological and psychological influences on postoperative fatigue. Anesth Analg. 2002;95(5):1446-50. table of contents

11. Gerbershagen HJ, Pogatzki-Zahn E, Aduckathil S, Peelen LM, Kappen TH, van Wijck AJ, et al. Procedure-specific risk factor analysis for the development of severe postoperative pain. Anesthesiology. 2014;120(5): 1237-45.

12. Kalkman CJ, Visser K, Moen J, Bonsel GJ, Grobbee DE, Moons KG. Preoperative prediction of severe postoperative pain. Pain. 2003;105(3):415-23. Epub 2003/10/07. eng.

13. Sommer M, de Rijke JM, van Kleef M, Kessels AG, Peters ML, Geurts JW, et al. Predictors of acute postoperative pain after elective surgery. Clin J Pain. 2010;26(2):87-94.

14. Peters ML, Sommer M, van Kleef M, Marcus MA. Predictors of physical and emotional recovery 6 and 12 months after surgery. Br J Surg. 2010;97(10): 1518-27.

15. Langford DJ, Schmidt B, Levine JD, Abrams G, Elboim C, Esserman L, et al. Preoperative breast pain predicts persistent breast pain and disability following breast cancer surgery. J Pain Symptom Manage. 2015;49(6):98194.

16. Peters ML, Sommer M, de Rijke JM, Kessels F, Heineman E, Patijn J, et al. Somatic and psychologic predictors of long-term unfavorable outcome after surgical intervention. Ann Surg. 2007;245(3):487-94. Pubmed Central PMCID: 1877005

17. Masselin-Dubois A, Attal N, Fletcher D, Jayr C, Albi A, Fermanian J, et al. Are psychological predictors of chronic postsurgical pain dependent on the surgical model? A comparison of total knee arthroplasty and breast surgery for cancer. J Pain. 2013;14(8):854-64.

18. Archer KR, Seebach CL, Mathis SL, Riley 3rd LH, Wegener ST. Early postoperative fear of movement predicts pain, disability, and physical health six months after spinal surgery for degenerative conditions. Spine J. 2014;14(5):759-67.

19. Kinjo S, Sands LP, Lim E, Paul S, Leung JM. Prediction of postoperative pain using path analysis in older patients. J Anesth. 2012;26(1):1-8. Pubmed Central PMCID: 3720127

20. Sommer M, de Rijke JM, van Kleef M, Kessels AG, Peters ML, Geurts JW, et al. The prevalence of postoperative pain in a sample of 1490 surgical inpatients. Eur J Anaesthesiol. 2008;25(4):267-74.

21. Gerbershagen HJ, Dagtekin O, Rothe T, Heidenreich A, Gerbershagen K, Sabatowski R, et al. Risk factors for acute and chronic postoperative pain in patients with benign and malignant renal disease after nephrectomy. Eur J Pain. 2009;13(8):853-60.
22. Johansen A, Romundstad L, Nielsen CS, Schirmer H, Stubhaug A. Persistent postsurgical pain in a general population: prevalence and predictors in the Tromso study. Pain. 2012;153(7):1390-6.

23. Schnabel A, Pogatzki-Zahn E. Predictors of chronic pain following surgery. What do we know? Schmerz. 2010;24(5):517-31. Pradiktoren fur chronische Schmerzen nach Operationen. Was wissen wir wirklich?

24. Macrae WD, HTO. In: Crombie IK, Linton S, Croft P, Von Korff M, LeResche L, editors. Chronic postsurgical pain. 1999th ed. Seattle: IASP Press; 1999. p. 125-42.

25. Brander VA, Stulberg SD, Adams AD, Harden RN, Bruehl S, Stanos SP, et al. Predicting total knee replacement pain: a prospective, observational study. Clin Orthop Relat Res. 2003;416:27-36.

26. Gerbershagen HJ, Ozgur E, Dagtekin O, Straub K, Hahn M, Heidenreich A, et al. Preoperative pain as a risk factor for chronic post-surgical pain - six month follow-up after radical prostatectomy. Eur J Pain. 2009;13(10):1054-61.

27. Gerbershagen HJ, Ozgur E, Straub K, Dagtekin O, Gerbershagen K, Petzke F, et al. Prevalence, severity, and chronicity of pain and general health-related quality of life in patients with localized prostate cancer. Eur J Pain. 2008; 12(3):339-50.

28. Sandblom G, Carlsson P, Sigsjo P, Varenhorst E. Pain and health-related quality of life in a geographically defined population of men with prostate cancer. Br J Cancer. 2001;85(4):497-503. Pubmed Central PMCID: 2364104.

29. Hauser W, Bock F, Engeser P, Tolle T, Willweber-Strumpfe A, Petzke F. Longterm opioid use in non-cancer pain. Dtsch Arztebl Int. 2014;111(43):732-40. Pubmed Central PMCID: 4238316

30. Armaghani SJ, Lee DS, Bible JE, Archer KR, Shau DN, Kay H, et al. Preoperative opioid use and its association with perioperative opioid demand and postoperative opioid independence in patients undergoing spine surgery. Spine. 2014;39(25):E1524-30.

31. Aasvang EK, Lunn TH, Hansen TB, Kristensen PW, Solgaard S, Kehlet H. Chronic pre-operative opioid use and acute pain after fast-track total knee arthroplasty. Acta Anaesthesiol Scand. 2016;60(4):529-36.

32. Veal FC, Bereznicki LR, Thompson AJ, Peterson GM, Orlikowski C. Subacute pain as a predictor of long-term pain following orthopedic surgery: an Australian prospective 12 month observational cohort study. Medicine (Baltimore). 2015:94(36), e1498. Pubmed Central PMCID: PMC4616644.

\section{Submit your next manuscript to BioMed Central and we will help you at every step:}

- We accept pre-submission inquiries

- Our selector tool helps you to find the most relevant journal

- We provide round the clock customer support

- Convenient online submission

- Thorough peer review

- Inclusion in PubMed and all major indexing services

- Maximum visibility for your research

Submit your manuscript at www.biomedcentral.com/submit 